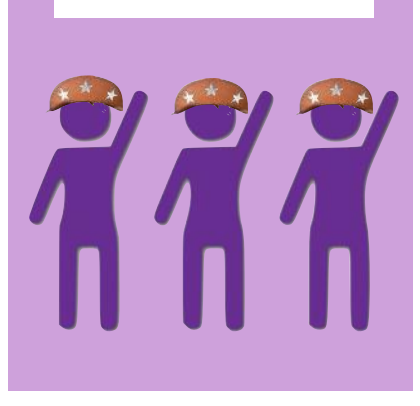

\title{
Pobreza e Sentido de Comunidade em Mulheres do Interior do Ceará:
}

Possibilidades de Intervenção a Partir da Psicologia Comunitária

Vilkiane Natercia Malherme BARBOSA, Universidade Federal do Ceará James Ferreira Moura JÚNIOR, Universidade da Integração Internacional da Lusofonia Afro-brasileira (UNILAB)

Verônica Morais XIMENES, Universidade Federal do Ceará

Resumo. Este trabalho busca analisar o impacto da pobreza no sentido de comunidade de mulheres do interior do Ceará a partir da Psicologia Comunitária. Partimos do reconhecimento das situações de desigualdades sociais e de gênero presentes no cenário brasileiro, podendo ter características mais intensas em territórios distantes dos grandes centros urbanos. Contudo, uma das estratégias de enfrentamento dessas iniquidades tem sido o sentido de comunidade, que pode fortalecer as relações socio-comunitárias. Realizamos uma pesquisa qualitativa com utilizaçao de entrevista semi-estruturada. Participaram dessa investigaçao dez mulheres em situaçao de pobreza de uma comunidade no interior do estado do Ceará. Foi utilizado a análise de conteúdo. As mulheres em cenários de pobrezas sofrem mais iniquidades do que os homens, porque existem macro estruturas sociais que fomentam modos de vida com diferentes oportunidades as pessoas a partir dos marcadores como raça, gênero e classe são relevantes para que façamos essa análise. Observou-se que relação destas mulheres em contexto de pobreza com o sentido de comunidade a partir das relações cotidianas estabelecidas. Assim, foram visibilizadas as opressões vividas e suas estratégias de enfrentamento, construindo estratégias para atuação em psicologia comunitária compromissada com a mudança das desigualdades sociais e de genero.

Palavras-Chave: Psicologia Comunitária. Pobreza. Sentido de Comunidade. Interseccionalidade. Comunidade. 


\section{Introdução}

Reconhece-se que contexto histórico- político no qual estamos imersos é marcado por retrocessos e avanço de posições conservadoras e autoritárias (LAVOR FILHO et al., 2018), fortalecendo estas estruturas de privilégios, em detrimento da subalternidade e opressão de outros (SOUZA, 2017; MAYORGA, 2014). Tal posição social de desigualdade torna injustas as possibilidades de agência dentre as pessoas, mesmo que estas vivam no mesmo território ou na mesma residência (CEPAL, 2017) A díade privilégio- opressão tem impactos diferentes entre mulheres e homens, negros e negras, pobres e ricos, dentre outros. Contudo, o que nos propormos não é uma soma ou sobreposição de marcadores identitários de diferença, mas a intersecção entre estes (CRENSHAW, 2002). Assim, tem-se como objetivo analisar o impacto da pobreza no sentido de comunidade de mulheres do interior do Ceará a partir da Psicologia Comunitária.

Considerando apenas o Ceará, podemos pontuar que 40\% da população se encontra abaixo da linha da pobreza (IBGE, 2019). Além disso, a concentração de renda no estado, no período avaliado de 2012 a 2018 aumentou, sendo que os 10\% com maiores rendimentos, recebem aproximadamente 15 vezes mais do que os $40 \%$ com menores rendimentos (IBGE, 2019). Este é um valor superior à média nacional. Estes dados alarmantes apontam para a necessidade de investigar e afrontar as condições de pobrezas e desigualdades sociais vividas tanto no Brasil, quanto no contexto cearense. Deste modo, compreender a categoria de Sentido de Comunidade é central para atuação teóricoprática no campo da Psicologia Comunitária, visto que esta categoria se conecta intrinsecamente com a produção de cuidado psicossocial implicada com enfrentamento das desigualdades sociais e da pobreza. Como pontua Sarriera et al. (2016), o sentido de comunidade é relevante para atuação de psicólogos no campo da intervenção comunitária, visto que este tem caráter transversal.

Aqui cabe a discussão de que a compreensão de Pobreza defendida, é a da Pobreza Multidimensional, baseada nas capacitações. Entendemos que a pobreza vai além da privação econômica, de não ter dinheiro, trata-se de um somatório de privações que atravessam profundamente os modos de vida das pessoas e suas trajetórias. E afeta não apenas as questões biológicas e/ou diretamente relacionadas à 
sobrevivência, mas a própria identidade e a constituição de si enquanto sujeito social (MOURA JR, 2015).

Desta forma, a pobreza tem consequências diretas na vida social e individual das pessoas, representando um modo de vida mais exposto a vulnerabilidades sociais, a falta de acesso a cidadania, a cultura, a educação, a saúde, ao saneamento básico dentre outros. Há influência nos modos de vida sociais e individuais das pessoas, assim como a percepção que carregam sobre o lugar onde vivem e de si próprias.

Souza (2017) pontua que existem três capitais relevantes para pessoas de quaisquer classes sociais, sendo estes: econômico, cultural e das relações sociais, e estes mediam as possibilidades de vida, de acesso à bens e a serviços que uma pessoa pode ter. No caso das pessoas em situações de pobrezas, ou como pontua este autor, há privação de acesso em todos estes âmbitos, o que cerceia as possibilidades de vida, dignidade e existência. Esta parcela da população é excluída, indesejada e explorada pelas demais classes sociais, que se beneficiam e sustentam seus privilégios sobre a subsistência e subordinação desta.

Tendo entendimento sobre os mais diversos e perversos efeitos das pobrezas sobre os modos de vida e trajetórias das pessoas e reconhecendo que mesmo em tais cenários é possível reconhecer estratégias de resistências é que se pensa relevante investigar, a relação entre $o$ sentido de comunidade e a pobreza multidimensional. Especialmente, porque embora reconheçamos o sentido de comunidade como fator protetivo, é também evidente que os mecanismos de ação das pobrezas, especialmente considerando esse sistema capitalista e opressor, são cada vez mais sutis e influenciam de forma profunda os modos de subjetivação das pessoas, as encarcerando em ciclos de dominação (GÓIS, 2012; SOUZA, 2017).

A Psicologia Comunitária nestes contextos de crise social em que vivemos, como pontua Moura Jr (2018), precisa ter uma atuação que considere no âmbito de sua práxis, especialmente junto as pobrezas, práticas que levem em consideração de forma ampliada as questões de raça, gênero, dentre outros marcadores sociais da desigualdade. Que nos contextos sócio-políticos vividos, tornam ainda mais centrais a relevância de uma atuação que tenha como cerne o fortalecimento comunitário.

Góis (2012), também pontua, que a Psicologia Comunitária precisa se afiliar a uma práxis libertadora que esteja voltada aos processos e modos de vida comunitários, que incluem os sentidos, sentimentos e 
significados empreendidos pelas moradoras e moradores nos espaços sociais, nas interrelações e na constituição da própria comunidade. Assim, a intervenção comunitária em contextos de pobrezas, violências e desigualdades sociais vividos exigem do campo da Psicologia Comunitária um esforço teórico-prático para com a construção de uma ciência decolonial com cunho interventivo e que apresente um compromisso ético e político para com os emancipação das minorias sociais (MAYORGA, 2014).

Segundo Freire (2003), a intervenção social que se reconhece como implicada, precisa, por necessidade, se assumir e se reconhecer como política. Pois é uma necessidade pensarmos criticamente, e aprendermos a sermos comunitários e a pensar no todo, mesmos em relação a nós mesmos. $\mathrm{E}$ que isto infere uma ética humana consigo, com o(a) outro(a) e com o mundo. Este mesmo autor afirma que a ética é essencial para o afrontamento das condições opressoras e seus efeitos sobre os modos de vida e as discriminações de classe, gênero e raça.

Portanto, consideramos relevante que possamos dialogar com uma concepção de sentido de comunidade próxima as experiências dos povos latino-americanos. Encontramos assim, a conceituação feita por González e Luna (2014) onde prevalece a compreensão do sentido de comunidade como expressão do nosotros, que resgata o sentido ontológico de um ser comunitário.

Nosotros, segundo as autoras significa a priori uma aproximação com os povos originários da América Latina, especialmente do México. É um conceito que revela uma constituição de ser comunitário atravessada pela indissociação das relações entre pessoa e comunidade (vice-versa) e pessoa e território (vice-versa) (GONZÁLEZ; LUNA, 2014). González (2015) aponta que o sentido de nosotros diz de um suporte a vida comum. Há assim, a partir da expressão de nosotros uma congruência entre o que se sente, o que se diz, se pensa, e como se vive, que perpassa, o reconhecimento da diversidade das pessoas que compartilham o mesmo território. Ao mesmo passo, há também o reconhecimento de um sentimento de pertença partilhados pelos membros do grupo, que ao passo que valoriza as experiências individuais, fortalece a ideia de ser, fortalecendo as relações entre as pessoas e entre estas e a comunidade (GONZÁLEZ,2014).

O sentimento de pertença atravessa uma possibilidade de resistência comunitária, no sentido, que permite a consciência de que 
mesmo considerando as singularidades das pessoas, há questões sociais, culturais, históricas, econômicas compartilhadas por todas e todos os membros da comunidade. A partir de um senso comum, é possível produzir estratégias de enfrentamentos das situações de opressão (GONZÁLEZ, 2015).

Assim, por meio da expressão de nosotros é possível compreender que o ser comunitário é um ser na primeira pessoa do plural, pois reconhece que as pessoas mesmos nas suas diferenças e subjetividades compartilham de experiências que as aproximam de um senso comum, tendo em vista que as questões vividas no seio da comunidade não podem ser refletidas apenas num âmbito individual, mas a partir de um processo de tomada de consciência coletiva (GÓIS 2012; GONZÁLEZ, 2014).

O fortalecimento da identidade, enquanto ser comunitário plural, fortalece a expressão de nosotros, a partir de um processo de tomada de consciência, que facilita o reconhecimento enquanto comunidade, não apenas no sentido de identificar demandas, fragilidades, e sofrimentos, mas de identificar as fortalezas deste território e das pessoas que o constituem a partir da próprio senso comum de ser comunidade (GONZÁLEZ; LUNA, 2014).

De tal maneira, a aproximação do sentido de comunidade como expressão de nosotros também perpassa o reconhecimento e investimento no sentido de comunidade que compreenda as diferenças étnico raciais, culturais e sociais, entre as comunidades, especialmente considerando as comunidades originais que historicamente sofrem processos de colonialidade que produzem, dentre outras consequências, invisibilização das suas próprias histórias e culturas (GONZÁLEZ; LUNA, 2014). Desta forma, os componentes que devem ser considerados para uma análise do sentido de comunidade devem estar associados aos modos de vida, as subjetividades e as realidades sociais em situação de marginalização (GONZÁLEZ, 2014). E é a partir deste que será construída a análise desta categoria nesse trabalho.

Pois para a Psicologia Comunitária trabalhar a partir de uma perspectiva de nosotros, de resgate da união e do senso de pertença de se sentir nosotros pode ser um processo catalisador para as pessoas em espaços comunitários, para que atuem, reflitam de forma conjunta sobre os processos de dominação e opressão vividos, tendo maior eficácia nas suas ações. Isso é necessário, porque em uma comunidade fragmentada e sem processo de conscientização há poucas possibilidades de produção de 
formas de resistência comunitária e de fazer-se nosotros para a luta (GONZÁLEZ, 2015).

Entende-se que o Brasil é um território marcado por desigualdades sociais e de pobreza, desta forma, o que se pretende é a construção de conhecimento aliado a uma perspectiva de enfrentamento das pobrezas, do fortalecimento das identidades comunitárias e individuais a partir da compreensão do sentido de comunidade e suas relações com as dimensões psicossociais da pobreza (GÓIS, 2012).

Mayorga (2014) pontua que as feministas negras têm problematizado e construído importantes críticas ao reconhecimento da opressão das mulheres a partir do gênero como única forma de dominação. Para estas, é relevante dar importância às exclusões, opressões e discriminações vividas relacionadas a outros marcadores como a sexualidade, geração, raça e a classe e desenvolver seus conceitos de gênero do feminismo a partir de um viés interseccional. Assim, tomamos como relevante construir esta análise a partir desta perspectiva de gênero sobre os contextos de pobreza e sobre o sentido de comunidade. Ao mesmo passo, deve haver uma estratégia de visibilização das diferenças e desigualdades vividas por mulheres no contexto em análise, como também, para o afrontamento das mesmas. A decisão de não tomar a priori a raça como marcador, embora, reconheçamos que tratamos em sua maioria de mulheres não- brancas, está em não delimitar por estas o reconhecimento de raça.

É sabido que no Brasil o "mito da democracia racial" como forma de dominação produziu no âmbito histórico-cultural das pessoas, especialmente as minorias subordinadas, mas não só destas, consciente (ou não) um modos operante de negação da negritude e de tudo que relacione a mesma (SOUZA, 2000). Tal medida fomentou e ainda fomenta o desejo pela branquitude, a partir das tentativas de identificação, imitação e/ou subordinação a mesma (CARDOSO, 2014). Esta ideia de democracia racial é uma falácia que sustenta o patriarcalismo, fortalecendo as estruturas sociais dominantes em seus lugares de privilégios (SOUZA, 2000). O que Souza (2017) aponta é que no Brasil, há uma racialização da pobreza, mas sem uma discussão das origens coloniais dessas desigualdades e injustiças sociais, as pessoas que estão nesta condição de iniquidades, são as que todas as outras classes querem se diferenciar. No outro extremo, a classe de privilégios, que não por coincidência é hegemonicamente branca e a que todos querem se aproximar.Para Diniz e Mayorga (2018, p. 9): “[...]resistir é negar a 
legitimidade da norma, é interpelar a submissão à regra externa; é, sobretudo, desnudar a arbitrariedade da dominação. Nesse sentido, a microrresistência, investida de poder".

Assim, pensamos nas estratégias de resistência e de enfrentamentos que as mulheres, neste caso específico, mas também negros (as), LGBTI+, imigrantes, dentre outras minorias possuem, possibilita a expansão da autonomia das mesmas nas relações sociais. Mesmo que estas relações ainda se constituam a partir de matrizes racistas, patriarcais e classistas, há um processo crescente que produz furos nas identidades cristalizadas destas pessoas a partir de novas formas de subjetivação a partir da emancipação humana.

Desta forma, a Psicologia Comunitária precisa considerar a relevância de possuir implicação teórica- prática com as questões de gênero, especialmente sobre um viés feminista. Pois este campo teórico prático que tem se implicado historicamente com os enfrentamentos das opressões e desigualdades (GÓIS, 2012). Assim, pode ser uma importante ferramenta para o fomento de intervenções socio-comunitárias comprometidas com a construção de realidades menos marcadas pelo eixo da opressão (MAYORGA, 2014).

\section{Metodologia}

Foi desenvolvido um delineamento de pesquisa do tipo qualitativo, que como aponta Minayo (2007) compreende a pesquisa como atividade intrinsecamente vinculada à existência humana, a realidade concreta, partindo de uma proposta metodológica que visa à aproximação dos pesquisadores (as) com a realidade social em estudo e a compreensão do fenômeno humano psicossocial e subjetivo.

$\mathrm{O}$ método de pesquisa utilizado parte da abordagem qualitativa com o viés interseccional. Segundo os autores Christensen e Jesen (2012), este viés possibilita analisar a categoria gênero combinada a outras categorias de análises possibilitando uma interação complexa entre gênero e as diferenciações sociais presentes nas estruturas de poder machistas, classistas, racistas e patriarcais que nos cerceiam. Deste modo, estas estruturas devem ser levadas em conta nas investigações que consideram gênero como categoria de análise, e mais, deve se reconhecer a indissociabilidade desta categoria com outros marcadores sociais da 
A PARTIR DA PSICOLOGIA COMUNITARIA

diferença, por isto, a necessidade de uma análise interseccional (DINIZ; MAYORGA, 2018).

\section{Local de Realizaçao}

Embora não haja a intenção de aprofundamento de outros marcadores, é relevante situar algumas questões para tal construção. A primeira diz respeito ao território de atuação, se tratando do interior do Ceará, questões étnicas- raciais devem ser levadas em consideração para o entendimento do que é ser homem e do que é ser mulher em tal contexto. Entendemos que o bairro é composto por maioria de mulheres, e que estas desenvolvem diferentes papéis sociais. Ainda assim, uma ligeira maioria ainda é dona de casa e/ou acumula esta função junta a outras possibilidades de trabalho.

\section{Participantes da Pesquisa}

As participantes da pesquisa foram dez mulheres moradoras da comunidade em análise. A maioria da amostra é composta por mulheres não- brancas (7) e com idades variando de 26 a 72 anos, vivendo na localidade há mais de dez anos. Estas foram escolhidas a priori a partir da inserção comunitária e do reconhecimento de lideranças. Algumas destas participantes são reconhecidas como lideranças não - formais do território e outras foram indicadas por estas a partir do procedimento bola de neve (CRESWELL et al., 2010). Foram dados nomes fictícios as participantes, que não tem relação com suas trajtórias de vida. Os nomes escolhidos são de mulheres, em sua maioria não-brancas, com trajetórias de luta e resistencia no nordeste do Brasil. Processo de pesquisa - relatar como forma as entrevistas quais o temas abordados, onde foram realizadas e tudo mais.

\section{Análise do Dados}

Após a realização das entrevistas, houve o processo de transcrição literal destas. Estas foram categorizadas a partir de categorias dedutivas relacionadas a macro temáticas da pobreza, desigualdade social e de gênero e sentido de comunidade, como também de categorias indutivas encontradas a partir da análise do material empírico (MINAYO, 2007). 
Para este processo de categorização do conteúdo de análise foi crucial a perspectiva interseccional Christensen e Jesen (2012).

\section{Questões Éticas}

Foi considerada a resolução de ética na pesquisa $510 / 2016$, que diz respeito às questões éticas de pesquisa com seres humanos, definindo critérios, delimitações, entre outros aspectos referentes à pesquisa com seres humanos que priorizam em seu cerne a vida e a dignidade humana. E este trabalho seguiu as normas e procedimentos éticos desta resolução. E este trabalho foi submetido e aprovado no Comitê de Ética.

\section{Resultados e Discussão}

Importante pontuar que as mulheres participantes desta pesquisa, por mais que vivam no mesmo território, possuem distintas caraterísticas, que modificam o modo como percebem a comunidade, as questões de pobrezas, de gênero e a si mesmas. Estas são mulheres em situação de pobreza, pertencentes a comunidade numa região do interior do Ceará, e em sua maioria, não- brancas. E que estes marcadores sociais representam o reconhecimento da diversidade e da pluralidade da categoria mulher, especialmente neste contexto. Pensar a categoria mulher como universal e embasar práticas que não reconheçam as diversidades possíveis a esta fortalecem a violência e a subordinação operadas sobre as mulheres não-brancas, que não estão incluídas nessa universalidade burguesa (ESPINOSA et al., 2017). Assim, Crenshaw (2002) aponta que as discussões no âmbito do feminismo precisam perpassar a tríade gênero, classe e raça numa perspectiva interseccional, reconhecendo os processos de discriminação e exclusão a partir destes e de outros marcadores sociais das diferenças para um melhor afrontamentos das distintas e múltiplas formas de opressões.

Gonzaga (2015) situa que as mulheres têm sido colocadas historicamente numa posição de subalternidade. As suas possibilidades têm sido podadas por uma organização social machista, que tem limitado as possibilidades de modos de vida das mulheres. Desvela que em mesmo em cenários de pobrezas, as mulheres acabam sofrendo mais privações pela organização social patriarcal e machista. Tendo estas, por vezes, que assumirem duplas e/ou triplas jornadas de trabalho. Desta forma, Walsh 
(2017) aponta que é relevante nos colocarmos contra as estruturas sociais que não fomentem processos de emancipação humana e de liberdades individuais e coletivas. Para esta autora, é relevante o reconhecimento e o afrontamento destas estruturas que desumanizam e subalternam as pessoas às condições de pobrezas e desigualdades, especialmente as mulheres, que historicamente têm sido colocados nesta posição.

E essas hierarquias de classe, raça, gênero incidem sobre o acesso a espaços de poder que uma pessoa pode ou não ocupar. E, nestes cenários, as mulheres pobres e não-brancas são as mais privadas (BERNARDINO- COSTA, 2015). O que apontamos é que existe uma sequência de desvantagens a estas mulheres, que são ocasionadas pelas posições em que estas ocupam, mantidas a partir dessas hierarquias opressoras (BIROLI, 2018). E isto afeta as identidades das mulheres e suas ações e/ou possibilidades de ações frente ao mundo (MAYORGA, 2014).

Tendo em vista isto, as autoras Espinosa et al. (2017) têm considerado a relevância de um feminismo descolonial, que tenha como práxis a transformação das relações sociais de opressão e subordinação a que as mulheres pobres, negras e indígenas têm sofrido. Fortalece-se, assim, processos de libertação e afirmação das múltiplas possibilidades comuns e singulares dos modos de vida e produção de subjetividade dessas mulheres. Neste sentido, apresentamos os achados encontrados a partir das entrevistas realizadas com estas mulheres.

Estes efeitos perpassam as questões quantitativas mais visíveis das pobrezas e afetam também as questões qualitativas, menos visíveis (DEMO, 2008). Acreditamos que visibilizar estas questões menos visíveis a partir das falas das entrevistadas seja relevante para os objetivos do estudo. Desvelar-se a partir das realidades das mesmas como as pobrezas se dão dentro de suas trajetórias e em seus cotidianos, entendendo que seus marcadores sociais continuam sendo relevantes para análises que faremos a seguir.

Por mais que partamos de uma concepção de pobreza multidimensional, não necessariamente será desta concepção que as participantes centraram suas opiniões, porque há hegemonicamente uma concepção de pobreza unidimensional, e na maioria das vezes, centrada na dimensão econômica (LAVOR FILHO et al., 2018). Neste sentido, é que 
se encontra a relevância de contextualizar o lugar que estas participantes partem para construir tais opiniões, porque estas opiniões partem, muitas vezes, de suas trajetórias pessoais, como do contexto sociopolítico macrossocial. Ao serem indagadas sobre o que é pobreza, algumas respostas possíveis foram:

Tem tanto, que a gente não sabe nem o quer que diga. Aí, o presidente entrou, nada tá fazendo. O quer que tá fazendo, né? Desempregando um bocado de gente aí, é isso, só isso. Como na Universidade né, aí, desempregou um bocado de gente, e a pessoa tem que aceitar. E aja pobreza, a gente tudo dentro de casa, não é não? Só isso. (Trecho de Entrevista de Esperança Garcia).

Porque não tem emprego, né. O presidente tá aí fazendo um bocado de coisa aí mulher, a gente só fica vendo, vendo, vendo no jornal e calado, calado, calada né. De quem é a culpa? É da gente mesmo, que a gente coloca esse povo aí , né, no poder e fica desse jeito. Pode não. A pessoal tudo desempregado, a maioria por aí, tem gente que vive dos, dos aposentos dos pais né? Os filhos dentro de casa. É, aqueles que tem muito menino, como é... acho que passa é fome, é. (Trecho de Entrevista de Dadá)

Pobreza é você não ter como, sobreviver né? Não ter chance de trabalho, de estudo não é? Porque é uma situação bem difícil, bem precária. (Trecho de Entrevista de Margarida Alves).

Ausência de recursos financeiros, mas também, a falta de acesso a políticas públicas também. (Trecho de Entrevista de Lia de Itamaracá).

Pobreza eu acho que é quando a pessoa não tem a oportunidade de conquistar nem o alimento, e nem moradia eu acho que é, porque a gente pobre, a maioria é pobre, mas tem o alimento e tem a moradia, eu acho que tem tudo. Pobre é que não tem condição de ter o alimento todo dia e uma moradia digna (Trecho de Entrevista de Elisabeth Teixeira).

Estas concepções de pobrezas aportam para o reconhecimento da dimensão trabalho e renda das pobrezas com o atravessamento das políticas governamentais inclusive de perceber, que existem perspectivas de gerenciamento de políticas que favorecem ou desfavorecem o enfrentamento das pobrezas (SOUZA, 2017; LAVOR FILHO et al., 2018). É perceptível que depois de 2016, quando houve o golpe de estado, destituindo a presidente eleita Dilma Rousseff e hoje com o (des)governo antidemocrático vigente, houve um aumento das pobrezas e das desigualdades sociais no país (BIROLI, 2018).

Importante lembrar que com o Decreto $\mathrm{N}^{\circ}$ 9.759, de 11 de abril de 2019, do atual presidente antidemocrático, extingui e suprimi a participação social, garantida pela Constituição Federal, dos 700 
conselhos existentes, sobrevivendo cerca de 50 conselhos (BRASIL, 2019). Além de outras manobras para impedir e/ou diminuir a participação social de centenas de pessoas representantes de classes e/ou minorias, o que na prática enfraquece a participação e o controle social sobre as políticas públicas.

Podemos inclusive pontuar que há uma perspectiva de estado atual, embalada pelos atuais governantes antidemocráticos, de aniquilamento de minorias. Estas tem sofrido o efeito, com mais evidência, dos cortes realizados em políticas públicas de assistência social, saúde e educação numa tentativa vil de desmantelar as estratégias e ações garantidas por lei e pela constituição federal de garantia de direitos básicos, como a saúde, educação, a moradia, a alimentação, dentre outros. Esse processo torna-se ainda mais violento e torpe, porque utiliza mecanismos neoliberais que fomentam a culpabilização pelas pobrezas, inclusive a do país, às pessoas que são mais afetadas pelos efeitos das pobrezas (BIROLI, 2018) além de prever uma desresponsabilização do estado em relação a esta questão.

Contudo, embora haja forças que trabalhem em prol de uma culpabilização do jeito pelas condições de pobrezas vividas, há também resistências a este movimento, no sentido, de reconhecimento das estruturas macrossociais que desvelam processos de desigualdades sociais (MAYORGA, 2014). Neste sentido, reverbera também a compreensão das pobrezas como causadas por essas desigualdades, que fomentam concentração de renda e privilégios a terminadas classes, e miséria a outras (SOUZA, 2017). Como pode ser possível observar na seguinte fala:

Essa falta de oportunidade né? Que existe. Às vezes, muitas vezes por ter, por a renda está só concentrada em uma determinada classe, não ter, não se pensar em outras políticas pra abranger, pra expandir. (Trecho de Entrevista de Maria Bonita).

Podemos inferir a partir disto, que as condições de vidas das pessoas em situação de pobreza se tornam ainda mais difíceis a partir do contexto socioeconômico vigente. No caso brasileiro, há uma expansão das iniquidades sociais (BIROLI, 2018), que são um mecanismo de expansão das desigualdades sociais e da supremacia de determinada classe social sobre as outras (SOUZA, 2017).

Importante também pontuar que há outras concepções de pobrezas expressas por estas mulheres. Elas desvelam outra característica 
do contexto comunitário, como a religiosidade. Então, quando questionadas sobre pobrezas, muitas respostas se encaminharam nesse sentido, apresentando múltiplos significados de pobreza, que apontam outras possibilidades de significar a mesma relacionada a religiosidade, como pode ser visto nas falas a seguir:

Pobreza (pausa) existe vários tipos de pobreza, pobreza de espírito, da alma, do coração, mesmo que a pessoa não tenha nada que seja pobre, as vezes tem muito pobre que não tem nada e é rico de espírito. Eu acho que é isso (Trecho de Entrevista de Maria Firmina dos Reis).

Pobreza ela é (pausa) mesmo a pessoa pobre de bens materiais, mas sendo rico de espírito, de fé que tudo vai mudar, as coisas vão mudando né? (Trecho de Entrevista de Soledad Barrett).

É, é espírito mesmo pobre, meu espírito não é pobre, eu sou pobre, e não tenho inveja de ninguém, eu só tenho inveja de uma coisa na minha vida, de quem tem fé, eu acho que tem fé bonito, se eu pudesse eu teria muita fé, (Trecho de Entrevista de Nísia Floresta).

Neste sentido, é possível compreender que para o contexto em análise, há uma clara associação entre o significado de pobrezas e a religiosidade, sendo um processo de reconhecimento dos aspectos religiosos como centrais para o contexto vivido. $\mathrm{E}$ a falta desses aspectos é relevante para pontuarmos a existência ou não de pobrezas. E nos auxilia a compreender a dimensão multidimensional como ainda mais relevante para a compreensão das implicações psicossociais das pobrezas (XIMENESet al., 2019) por fomentar as possibilidades que outras dimensões, que não só a econômica, sejam partes deste processo de compreensão.

Uma perspectiva multidimensional de pobrezas possibilita reconhecer a complexidade deste fenômeno e suas nuances, com outras dimensões não tão conhecidas e com impactos menos visíveis inclusive pouco citadas nas mensurações oficiais sobre pobrezas (MOURA JR, 2015). Assim, neste contexto tornou-se importante apontar essa relação, porque as experiências e trajetórias destas mulheres pontuaram esta intersecção, não apenas para significar as pobrezas, como também, as implicações psicossociais desta. Como podemos apontar, na seguinte fala, que conectam as causas das pobrezas relacionadas as questões divinas, que se aproximam de uma visão fatalista. Como pode ser visto a seguir:

Aí a mulher pobre, que não tem trabalho, que quer luxar sem poder, pois aceite sua pobreza né? Aceite do jeito que você é né? Porque é como, Deus fez assim. Se Deus não me deu uma riqueza é porque eu tenho que ser só 
aquele tantinho que Deus me deu né? Tem que aceitar o que Deus dá. Se Deus deu a outros mais alguma coisa, é porque aquele ali mereceu, tem que ter. Mas, ou então se tem alguma coisa é roubado, roubado é que não dá né? É pior. Pois é mulher, é isso aí. (Trecho de Entrevista de Laudelina Campos).

Para Cidade (2019), o fatalismo é um dos efeitos vivenciados pelas condições de vida em situação de pobrezas, se manifesta pelo presenteísmo, pessimismo, predestinação e controle divino. E a fala de Laudelina trata destas duas últimas características do fatalismo. São aportadas as causas das pobrezas a uma predestinação ocasionada por uma força maior, que não pode ser questionada e/ou afrontada. Partindo então, de uma explicação simplista e mística sobre as causas das pobrezas, não há uma reflexão crítica sobre as mesmas (GÓIS, 2012). Existem também concepções de pobrezas relacionadas a perspectivas fatalistas, de acomodação pela condição de pobreza vivida, como no trecho a seguir: "Então eu sempre aceitei, eu nunca me preocupei, porque eu sou pobre, porque fulano tem e eu não tenho. Eu nunca sofri e eu sempre fui pobre, e eu fui muito pobre" (Trecho de Entrevista de Nísia Floresta).

Neste processo, a própria pessoa que vive em situação de pobreza se reconhece a partir do lugar de resignação e opressão (GÓIS, 2012). Essa identidade de oprimida e resignada se associa a processo de acomodação e fatalismo em relação à pobreza, à medida que este, parece cristalizado, sem possibilidades de mudanças. Pode acarretar sentimentos de desagregação e despontecialização da pessoa em situação de pobrezas, repercutindo no isolamento comunitário, que pode fragiliza-la e deixa-la mais vulnerável às múltiplas formas de violência (MARTÍN- BARÓ, 2011).

Dentro desta concepção de culpabilização da pessoa, há também uma perspectiva sobre a própria condição de estar em pobreza, baseada na trajetória pessoal, como argumento de culpabilização de pessoas em condições de pobrezas análogas as vividas na sua trajetória, em especial pelos sentimentos relacionados à essa condição. É uma perspectiva que não apenas culpabiliza, mas produz preconceitos, humilhação e vergonha a quem está em situação de pobrezas (MOURA JR, 2015). Como pode ser visto a seguir:

[...]mas eu acho que pobreza tem gente que gosta de ser assim ó coitadinho. $\mathrm{Eu}$, eu hoje eu continuo pobre, pobre de dinheiro o resto eu sou é rica, mas eu nunca me senti coitadinha Eu tinha cinco filhos, eu nunca dobrei minha cabeça e nem fiquei assim pensando, tão triste, tão pobre (pausa). E eu fui muito carente sim, mas eu nunca dei a saber ninguém (pausa), eu nunca 
gostei de me sentir coitadinha, velhinha doente, "ò uma velhinha tão doente"(Trecho de Entrevista de Nísia Floresta).

Há também um reconhecimento de culpabilização da pessoa, relacionando a condição de estar em situação de pobreza, ao comodismo, à falta de busca por trabalho e/ou aceitação de formas de trabalho menos valoradas. Para as entrevistadas, a não aceitação das pessoas em assumirem determinadas formas de trabalho, que para elas foi uma possibilidade de enfrentamento das pobrezas, é que faz com que os indivíduos fiquem em situação de vulnerabilidade social. Como pode ser visto a seguir:

Eu acho que a pobreza pra mulher mesmo é quando ela não tem é coragem de trabalhar, porque se a pessoa não tiver coragem de trabalhar né? Pra se sustentar, pra fazer alguma coisa. (Trecho de Entrevista de Maria Firmina dos Reis).

Mulher pobreza (pausar) no meio da pobreza (risos) tem mais é falta de coragem, porque tem gente que é tão preguiçoso que se julga ser pobre, pobre, que anda por ai pedindo, mendigando, mas não vai trabalhar. Nós dessa idade ainda trabalha tanto, cuida de neto, cuida de casa e cuida de tudo, ai tem alguém que passa nas portas da gente pedindo, e ai a gente pergunta "minha filha você não quer trabalhar não?" Ai ela diz assim pra gente ' não a minha mãe não deixa não, meu marido não deixa, meu pai não deixa, não sei quem não deixa". Quer dizer com isso daí que a pobreza de preguiça também né? Gente pobre preguiçoso, porque dentro de uma vez que você procura alguma coisa na vida, encontra. O povo disse que quem procura encontra, mas ai se tá se acostumando só em pedir, não tem pobreza. A pobreza é a preguiça é a falta de coragem em trabalhar. (Trecho de Entrevista de Laudelina Campos de Melo).

Eu nunca passei fome, eu nunca amanheci o dia e não uma coisa pra botar na minha panela, porque eu corria atrás. E hoje eu vejo gente nova, que não tem coragem de fazer nada (Trecho de Entrevista de Nísia Floresta).

Não teve, como se diz, coragem de enfrentar mesmo né? Aí se acomoda, é acomodação também a pobreza. Se acomoda muito, "ah, porque sou pobre, aí vou ficar ali sem procurar mais um emprego, sem procurar nada", acha que não tem chance. (Trecho de Entrevista Margarida Alves).

Esta discussão é relevante para desvelar que o discurso de culpabilização não é exclusivo das classes dominantes, embora se originem a partir desta. Há também entre os e as oprimidas pessoas que reproduzem estes discursos de culpabilização. Mesmo mulheres em situação de pobrezas opinam de forma depreciativa sobre as causas das pobrezas de outras mulheres nas mesmas condições. Este fenômeno é bem interessante, porque revela a potência das macroestruturas de poder 
classistas, patriarcais e racistas, que conseguem cumplices entre os oprimidos (CASTRO et al., 2017).

Neste sentido, entendemos que para as classes dominantes esse processo é relevante, porque favorecem a compreensão errônea da meritocracia, e não se produzem discussões mais profundas sobre as causas efetivas das pobrezas. Assim, as relações individuais e coletivas, especialmente em contextos comunitários, se tornam mais desagregadas, opressoras, passivas, influenciando diretamente na dinâmica psicossocial existente (SARRIERA, et al., 2016).

Contudo, o discurso de culpabilização, mesmo sendo hegemônico, na amostra em estudo, encontra dissidências. Uma delas é o reconhecimento destes sentimentos como a vergonha, a falta de esperança e humilhação, como legítimos e relacionados com as condições de pobrezas relatadas pelas participantes nas entrevistas. Estes sentimentos já foram apontados por Moura Jr (2015) como presentes nas experiências das pessoas em situação de pobrezas, pois, existem processos de culpabilização das pessoas por estarem em situação de pobrezas:

O que eu acho da pobreza, é angustiante né? Muitas vezes é perder a esperança. É você, às vezes acordar ao dia né? E não saber se vai ter almoço, vai ter jantar né? Ou se ter almoço sem saber se vai ter jantar, ou se você tem hoje e não saber como vai ser amanhã. Não só em relação a gente ter né? Um vestir né. Mas no sentido alimento né? Que o alimento é mais urgente né. $\mathrm{E}$ porque a gente sabe que o alimento é prioritário. Não adianta encher a barriga, nem sempre encher a barriga é ser alimentar né? Você pensa em fazer bucho né, faz aquela bucha, mas não se alimenta né. (Trecho de Entrevista Esperança Garcia).

Considerando os marcadores sociais de classe (entendendo que não falamos de qualquer classe, mas de pessoas em situação de pobrezas), território, gênero e geração, que foram mais evidentes a partir das análises realizadas, percebemos como estes dialogavam com a construção de sentido de comunidade que estas desenvolvem. Aportando a Jacob (2001), a partir de sua compreensão dos conceitos de comunidade e o de sentido de comunidade, uma das participantes ao ser indagada o que é o sentido de comunidade, respondeu o seguinte:

É porque eu preciso da minha comunidade, eu não sou nada sem a minha comunidade. Eu não sou nada, né? Eu me sinto assim feliz, porque eu sei que tenho essa pessoa, que vão de qualquer maneira incentivar na minha vida, a vida se torna mais feliz, mais agradável, a gente fica sabe mais "eu to com esse problema aqui, mas eu vou já ali, vou já conversar com fulano”. Aí chega lá você desabafar com aquela pessoa e você sente aquela gratidão de 
pertencer aquela comunidade, porque você sabe que você é da comunidade. A comunidade precisa da gente, e a gente precisa da comunidade, por que o que faz a comunidade não é as pessoas?! Não é a união das pessoas que faz a comunidade?! A comunidade é a união de pessoas, sobreviver perto daquelas pessoas (Trecho de Entrevista com a Participante Soledad Barrett)

Neste trecho há uma percepção que a própria comunidade é constituída a partir deste sentido de comunidade, atrelado ao sentimento de pertença e de emoções compartilhadas. O que corrobora com o Jacob (2001) que aponta que o sentido de comunidade é diferente do conceito de comunidade, mas o compõe. Não se pode pensar no mesmo desassociado da comunidade. Esta enquanto espaço geográfico, político, histórico, cultural, onde a vida e as relações entre e com as pessoas se realizam, possibilitando formas de vida em comum (GÓIS, 2012). E o sentido de comunidade enquanto possibilidade de suporte mútuo e apoio social comunitário, o que pode facilitar o processo de proteção social.

A fala da participante Soledad Barrett também aponta para um conceito de sentido de comunidade atrelado a ideia de pertencimento sendo uma das dimensões que compõe esse construto (Ximenes et al., 2019). Esse pertencimento também delimita a um lugar, as possibilidades de relações e modos de vida presentes que para participante é cercado pela união entre as pessoas, pelo apoio social entre os membros da comunidade. Desvela a possível existência de uma rede de relações pessoais para o suporte mútuo no espaço comunitário, numa perspectiva de ser em comum as outras pessoas. Perpassa a ideia de comunidade, enquanto espaço coletivo, onde as identidades individuais se fortalecem a partir do diálogo com as identidades coletivas da comunidade (GONZÁLEZ; LUNA, 2014).

Esta ideia foi muito comum entre as entrevistas, como podemos visualizar a parti da fala de outra participante Nísia Floresta: "Eu acho que o sentido de comunidade é a gente se unir, ser uma família, o que eu quero pra minha casa, você quer pra sua, e o que a gente quer pra o nosso bairro, todo mundo querer, que a gente mora aqui. Eu, meu modo de pensar é desse jeito." Fortalece-se o sentido de comunidade relacionado a expressão de nosotros, reconhecendo na estrutura sócio comunitária a percepção de modos de vida vinculados a uma perspectiva coletiva (GONZÁLEZ; LUNA, 2014). Em contrapartida, há uma visão 
individualista e utilitarista do território (GONZÁLEZ, 2015). Há uma preocupação em construção de vida em comum, em co-responsabilização pelas questões comunitárias, que são perpassadas por relações de proximidades entre os e as moradoras, que dividem anseios, sonhos e perspectivas de modos de vida, em ações para o bem viver (ACOSTA, 2016).

Apontamos que o sentido de comunidade enquanto expressão de nosotros tem dialogado junto com as realidades comunitárias como fator de proteção social e estratégia de resistência (GONZÁLEZ; LUNA, 2014). Assim, entendemos que, a partir da realidade vivida pelas pessoas em seus contextos, é possível construir e co-facilitar estratégias de intervenções psicossociais que tenham efeito político em suas vidas cotidianas (CIDADE; SILVA; XIMENES, 2019). Desta forma, reafirmamos a compreensão de um construto de sentido de comunidade que facilite processos de mudança social, à medida que o mesmo emerge com e a partir das pessoas, de seus significados e de suas vivências históricas (GÓIS, 2012; MARTÍN- BARÓ, 2011).

Importante pontuar que o sentido de comunidade sofre influências das dimensões das pobrezas. E que isto referenda as discussões levantadas por outros estudos, que afirmam que o sentido de comunidade é impactado pelas condições de vida das pessoas e seus contextos sociais (JACOB, 2001; GONZÁLEZ; LUNA, 2014; GONZÁLEZ, 2015; XIMENES, et al., 2019). E considerando, que neste estudo, há um atravessamento evidente dos marcadores sociais das participantes do mesmo, há também a compreensão que estes afetam o sentido de comunidade desenvolvido pelas mesmas.

Nas análises realizadas foi perceptível que estas mulheres se relacionam de forma distintas com o território. Esta relação parte de características particulares destas, tais como idade, religiosidade, dentre outras. Como também dos sentimentos de pertencimento, apoio mútuo, emoções compartilhadas e influência que sentem em relação as pessoas ao seu entorno e a comunidade como um todo. Desta forma, os sentimentos de comunidade como família e como importante foram os mais presentes. $\mathrm{E}$ os descontentamentos em relação ao território estavam 
mais relacionados a falta de ações coletivas para o bem comum e a falta e/ou ineficiência de fontes de renda relacionadas ao território.

Assim, pensamos como estratégia de intervenção ações relacionadas a geração de renda. Desta forma, a partir da inserção comunitária e do apoio da extensão universitária emerge a proposição de um grupo de mulheres para o desenvolvimento de tecnologia social. Sendo a tecnologia social a confecção de bolsas a partir de materiais recicláveis de baixo custo. Foi formado desta forma, este grupo de geração de renda a partir da confecção de bolsas. Contudo, os encontros com estas mulheres não tinham o objetivo apenas de ensinar a confecção das bolsas, mas a emancipação humana destas. Neste sentido, todos os encontros tinham temáticas relacionadas aos direitos humanos, participação comunitária e sentido de comunidade.

Para que estes objetos produzidos tivessem efeitos para além da renda, e atingissem outras dimensões da vida destas mulheres. Assim, eram utilizadas simbólos que as relacionavam com o que sentiam sobre a comunidade e reflitessem sobre seus modos de vida. Como também, os encontros tendiam as aproximar, para que estas pudessem funcionar como um grupo de apoio mútuo. Os encontros eram realizados semanalmente, e utilizavam de um espaço comunitário do território. Infelizmente, por conta do momento de pandemia, não tem sido possível a realização do mesmo.

Porém, já nos deu pistas que investir em intervenções que sejam feitas com este caráter de cooperação e apoio mútuo, numa perspectiva de geração de renda, pode ser bastante efetivo. Pois aproxima as pessoas, a partir do reconhecimento de suas necessidades em comum, as fazendo sentir que a partir do grupo podem ter apoio para suprir suas necessidades (JACOB, 2001). E como espaço de convivencia comunitário tem a potencia de gerar mais implicação com as questões comunitárias, facilitando os sentimentos de pertença destas mulheres com seu local (GONZÁLEZ, 2015).

\section{Considerações Finais}

Discutir a partir uma abordagem interseccional as questões de gênero imbricadas a pobreza e ao sentido de comunidade nos auxiliou 
perceber as dinâmicas comunitárias e os modos de vida destas mulheres. Evidenciou-se que as opressões sofridas por estas se relacionam as condições de pobrezas vividas, e sentimentos de culpabilização pela pobreza, fatalistas e de reconhecimento da pobreza como causada por forças maiores como comuns. O que corrobora com o que apresentamos sobre a necessidade de pensar a pobreza a partir de uma perspectiva multidimensional. Pois esta, tem efeitos nos modos de vida das pessoas para além da renda, afetando como se percebem e vivem seus modos de vida.

Também foi possível discutir a feminilidade da pobreza, pois as mulheres mesmo no mesmo contexto que os homens sofrem mais os efeitos das iniquidades relacionadas a pobreza. Contudo, estas também são a maioria das pessoas vivendo no território e tem relações de apoio mútuo e de pertencimento que tem sido estratégias adotadas por estas de enfrentamento das condições opressoras de vida.

Desta forma, fomentar ações que fortaleçam essas relações sociocomunitárias em prol de objetivos comuns e das necessidades individuais destas, pode ser uma estratégia de fortalecimento das mesmas e do tecido comunitário, como também de enfrentamento das pobrezas. Assim, as intervenções precisam dialogar com os modos de vida comunitários já desenvolvidos por estas mulheres e a partir destes facilitar processos que desenborquem em mudanças sociais. Como limitações do estudo, acreditamos que estudos futuros deveriam aprofundar as discussões acerca do marcador geracional, que embora não seja uma discussão pensada a priori, neste estudo, emerge como importante marcador social para entender as relações sociocomunitárias estabelecidas no território.

\section{Referências}

ACOSTA, A. O bem viver: uma oportunidade para imaginar outros mundos. Rio de Janeiro: Elefante Editora, Editora Autonomia Literária, 2016. 264 p. Tradução: BREDA, T.

BERNARDINO-COSTA, J. Decolonialidade e interseccionalidade emancipadora: a organização política das trabalhadoras domésticas no brasil. Revista Sociedade e Estado, Brasília, v. 30, n. 1, p. 147-163, 2015. 
Disponível em: https://www.scielo.br/pdf/se/v30n1/0102-6992-se-3001-00147.pdf. Acesso em: 12 maio 2018.

BIROLI, Flávia. Gênero e desigualdades: limites da democracia no brasil. São Paulo: Boitempo, 2018. 227 p.

BRASIL. Decreto $N^{o}$ 9.759, de 11 de abril de 2019. Atos do Poder Executivo. Diário Oficial da União: seção 1, Brasília, DF, edição: 70-A, p.5, órgão: Atos do Poder Executivo, 2019.

CARDOSO, L. $O$ branco ante a rebeldia do desejo: um estudo sobre a branquitude no Brasil. 2014. 290f. Tese (Doutorado) - Curso de Doutorado em Ciências Sociais, Faculdade de Ciências e Letras, Universidade Estadual Paulista Júlio de Mesquita. Araraquara, 2014. Disponível em: http://hdl.handle.net/11449/115710. Acesso em: $30 \mathrm{abr}$. 2018.

CASTRO, R. D. et al. Raça, gênero e classe: notas a partir de experiências de mulheres negras de classe média na ufmg. Interfaces Científicas Humanas e Sociais, [s.l.], v. 6, n. 2, p. 99, 16 out. 2017. Universidade Tiradentes. http://dx.doi.org/10.17564/2316-3801.2017v6n2p99-110. Disponível em: encurtador.com.br/ehrL6. Acesso em: 23 nov. 2018.

CEPAL, Nu. División de Estadísticas. Anuario Estadístico de América Latina y el Caribe 2016. 2. ed. Santiago: Cepal, 2017. 134 p. Disponível em: https://www.cepal.org/pt-br/node/41324. Acesso em: 25 abr. 2019.

CHRISTENSEN, A.; JENSEN, S. Q. Doing Intersectional Analysis: methodological implications for qualitative research. Nora - Nordic Journal Of Feminist And Gender Research, [s.1.], v. 20, n. 2, p. 109-125, jun. 2012. Informa UK Limited.

http://dx.doi.org/10.1080/08038740.2012.673505.

CIDADE, E. C. Estratégias psicossociais de enfrentamento à pobreza: um estudo sobre o fatalismo e a resiliência em pessoas residentes na zona rural brasileira. 2019. 295 f. Tese (Doutorado) - Curso de Doutorado em Psicologia, Programa de Pós- Graduação em Psicologia, Universidade Federal do Ceará, Fortaleza, 2019.

CIDADE, E. C.; SILVA, A. M. S.; XIMENES, V. M. Poverty and Youth: Psychosocial Implications, Ways of Life, and Coping with Daily Adversities. In: XIMENES, V. M.; MOURA JR, J. F.; CIDADE, E. C.; 
NEPOMUCENO, B. B. Psychosocial Implications of Poverty: diversities and resistances. Diversities and Resistances. Nova York: Springer Nature Switzerland, 2019. Cap. 14. p. 191-206.

CRENSHAW, K. Documento para o encontro de especialistas em aspectos da discriminação racial relativos ao gênero. Rev. Estud. Fem. [online], Florianopólis, v. 10, n. 1, p. 171-188, 2002. Disponível em: https://doi.org/10.1590/So104-026X2002000100011. Acesso em: 13 ago. 2018.

CRESWELL, J. W. Projetos de pesquisa: métodos qualitativo, quantitativo e misto. Artmed: Porto Alegre, 2010.

DEMO, P. Pobreza Política. 6. ed. Campinas: Autores Associados, 2008.

DINIZ, A. G. R.; MAYORGA, C. Notas sobre autonomia e desqualificação social de mulheres prostitutas. Psicologia \& Sociedade, Belo Horizonte, v. 30, p. 1-12, 14 nov. 2018. Disponível em: https://www.scielo.br/scielo.php? script=sci_abstract\&pid=So10271822018000100221\&lng=pt\&nrm=iso. Acesso em: 27 ago. 2018.

ESPINOSA, Y.; GÓMEZ, D.; LUGONES, M.; OCHOA, K. Reflexiones Pedagógicas em torno al feminismo descolonial: uma conversa em cuatro voces. In: WALSH, C. Pedagogías Decoloniales: Práticas Insurgentes de resistir, (re)existir e (re)vivir Tomo I. Serie Pensamiento Decolonial. Equador: Editora Abya-Yala, 2017. p. 403-441.

FREIRE, P. Pedagogia da autonomia: saberes necessários a prática educativa. São Paulo: Paz e Terra, v. 28, 2003. 148 p.

GÓIS, C. W. L. Psicologia clínico-comunitária. Fortaleza: Banco do Nordeste, 2012.

GONZÁLEZ, K. I. H. Resistencia comunitaria de los pueblos originarios: un espacio de acción del psicólogo con la comunidad. Eureka, Assuncíon, v. $12, \quad$ n. $1, \quad$ p. 48-72, 2015. Disponível em: https://psicoeureka.com.py/sites/default/files/articulos/eureka-12-m13.pdf. Acesso em: 21 set. 2018.

GONZÁLEZ, K. I. H.; LUNA, B. M. M. Sentido de Comunidad en un pueblo originario: santa martha acatitla (entre los carrizos). Coyocán: Editora Buena Onda, 2014. 180 p. 
GONZÁLEZ, K. I.H. Perspectiva psicosocial comunitaria de los pueblos originarios en la ciudad de México. El caso de Santa Martha Acatitla (entre los carrizos). Sentido de comunidad en un pueblo originario: Santa Martha Acatitla (entre los carrizos). México: Facultad de Psicología: UNAM, 2014.

IBGE, Coordenação de População e Indicadores Sociais. Síntese de indicadores sociais: uma análise das condições de vida da população brasileira: 2019. Rio de Janeiro: Estudos e Pesquisas. Informação Demográfica e Socioeconômica, 2019. 130 p. (40). Disponível em: https://biblioteca.ibge.gov.br/visualizacao/livros/liv101678.pdf. Acesso em: 16 dez. 2019.

JACOB, M K. Hacia una Redefinición del Concepto de Comunidad Cuatro Ejes para un análisis y una Propuesta. Chile: Revista de Psicología, v. x, n.2, p. 49-6o, 2001. DOI: 10.5354 / 0719-0581.2012.18572.

LAVOR FILHO, T.L.; BARBOSA, V.N.M. ALMEIDA SEGUNDO, D.S.; MOURA JR, J.F.; JANNUZI, P.M.; LIMA, R.S. Análises Interseccionais a Partir da Raça e da Classe: medo do crime e autoritarismo no brasil. Psicologia: Ciência e Profissão, [s.l.], v. 38, n. 2, p. 223-237, 2018. FapUNIFESP (SciELO). http://dx.doi.org/10.1590/19823703000212376 .

MARTÍN- BARÓ, I. Desafios e Perspectivas da Psicologia LatinoAmericana. In: GUZZO, R. S. L; LACERDA, JÚNIOR, F. Psicologia Social para a América Latina: o resgate da Psicologia da Libertação. São Paulo: Alínea, 2 ed., 2011. p.199-220.

MAYORGA, C. Some feminist contributions to community social psychology. Athenea Digital. Revista de Pensamiento e Investigación Social, [s.l.], v. 14, n. 1, p. 221, 17 fev. 2014. Universitat Autonoma de Barcelona. http://dx.doi.org/10.5565/rev/athenead/v14n1.1089.

MINAYO, M.C. O desafio do conhecimento: pesquisa qualitativa em saúde. São Paulo, Hucitec, 2007.

MOURA JR, J. F. Pobreza Multidimensional e Bem Estar Pessoal: um estudo acerca da vergonha e da humilhação. 2015. 210 f. Tese (Doutorado) - Curso de Doutorado em Psicologia, Programa de Pós- Graduação em Psicologia, Universidade Federal do Rio Grande do Sul, Porto Alegre, 2015.

Disponível em: 
https://www.lume.ufrgs.br/bitstream/handle/10183/140913/00099160 8.pdf?sequence=1. Acesso em: 09 abr. 2018.

MOURAJR, J. F. Psicologia Comunitária Revisitada: potências e lacunas em tempos de crise. Psicologia Política, São Paulo, v. 18, n. 42, p. 428432, 2018.

Disponível

em:

http://pepsic.bvsalud.org/pdf/rpp/v18n42/v18n42a15.pdf. Acesso em: 13 jun. 2019.

SARRIERA, J. C.; MOURA JR., J. F.; XIMENES, V. M.; RODRIGUES, A. L. Sentido de Comunidade como Promotor de Bem-Estar em Crianças Brasileiras. Porto Rico: San Juan, Interamerican Journal of Psychology, v.5o, n.1, p.106-116, 2016.

SOUZA, J. A elite do atraso: da escravidão à lava jato. Rio de Janeiro: Leya, 2017. $301 \mathrm{p}$.

SOUZA, J. Democracia racial e multiculturalismo: ambivalente singularidade cultural brasileira. Estudos Afro-asiáticos, [s.l.], n. 38, p. 135-155, dez. 2000. FapUNIFESP http://dx.doi.org/10.1590/s0101-546x2000000200007.

(SciELO).

XIMENES, V. M. et al. Sentimento de comunidade e pobreza rural no nordeste, norte e sul do brasil. Revista Subjetividades, Fortaleza, v. 19, n. 1, p. 1-13, 2019. Disponível em: encurtador.com.br/ayJ15. Acesso em: 18 dez. 2019. 


\section{Poverty and sense of community in women of the interior of Ceará: Possibilities of intervention from Community Psychology}

ABSTRACT: This study aims to analyze the impact of poverty in the sense of community of women of the interior of Ceará from the Community Psychology. We start from the recognition of the situations of social and gender inequalities present in the Brazilian scenario, which may have more intense characteristics in territories distant from large urban centers. However, one of the strategies of confrontation of these iniquities has been the sense of community, which can strengthen the social-communitarian relations. We conducted a qualitative survey using semi-structured interviews. Ten women in situations of poverty from a community in the interior of the state of Ceará participated in this research. Content analysis was used. Women in poverty scenarios suffer more iniquities than men, because there are macro social structures that foment ways of life with different opportunities people from the markers as race, gender and class are relevant for us to do this analysis. It was observed that the relationship of these women in the context of poverty with the sense of community from the established daily relationships. Thus, the oppressions experienced and their strategies of confrontation were made visible, building strategies for action in community psychology committed to changing social and gender inequalities.

KEYwORDs: Community Psychology. Poverty. Sense of Community. Intersectionality. Community.

Vilkiane Natercia Malherme BARBOSA

Universidade Federal do Ceará

Psicóloga formada pela Universidade Federal do Piaú. Doutoranda e mestre em Psicologia pela Universidade Federal do Ceará. Especialista em caráter de residência em Atenção Básica/Saúde da Família pela Universidade Federal do Piaú. Orcid: http://orcid.org/oooo-0002-3048-9316 e-mail: vilkimalherme@outlook.com

James Ferreira Moura JÚNIOR

Universidade da Integração Internacional da Lusofonia Afro-brasileira Doutor em Psicologia (UFRGS). Docente da Universidade da Integração Internacional da Lusofonia Afro-brasileira (UNILAB) e da Pós-graduação em Psicologia da Universidade Federal do Ceará (UFC), Fortaleza-CE, Brasil.

Orcid: http://orcid.org/oooo-0003-0595-5861 e-mail: jamesferreirajr@gmail.com

Verônica Morais XIMENES Universidade Federal do Ceará Doutora em Psicologia - Universidad de Barcelona (200o) e Pós-Doutorado em Psicologia da Universidade Federal do Rio Grande do Sul (2011). É professora Titular da Universidade Federal do Ceará e do Programa de Pós-graduação em Psicologia.

Orcid: http://orcid.org/oooo-ooo3-3564-8555 e-mail:vemorais@yahoo.com.br

Recebido em: 23/o6/2020

Aprovado em: 27/10/2021 